\title{
Analysis and Control of Low-Voltage Ride- Through Capability Improvement for PMSG Based on an NPC Converter Using an Interval Type-2 Fuzzy Logic System
}

\author{
Altan Gencer \\ Department of Electrical and Electronics Engineering, Faculty of Engineering and Architecture, \\ Nevsehir H.B.V. University, \\ 50300, Nevsehir, Turkey \\ altangencer@nevsehir.edu.tr
}

\begin{abstract}
Wind farms must be linked to the grid during the voltage sag. Therefore, the improvement of low-voltage ridethrough (LVRT) capability of wind turbine (WT) is a vitally issue. Protection system based on an interval type-2 fuzzy logic system (IT-2 FLC) is presented to improvement of LVRT capability of permanent magnet synchronous generator (PMSG) based on WT during the voltage dip. The presented control system prevents the power converters from the damaging effects of over-voltage during LVRT time. In addition to, the proposed protection system based on IT-2 FLC provides constant DC link voltage, reduces the amplitude of stator fault voltages, and enhances all response of PMSG. The proposed method is applied wind turbine using a 1.5MVA PMSG during different voltage sag types in the MATLAB/Simulation. The effectiveness of presented technique is verified by simulation results.
\end{abstract}

Index Terms-Permanent magnet synchronous generator; Low-voltage ride-through; Interval type-2 fuzzy logic system; Wind energy conversion.

\section{INTRODUCTION}

Recently, wind energy generates electricity from a renewable source that has attracted much interest [1]. Many types of generators are used in wind farms, and each has different advantages and disadvantages [2]. Permanent magnet synchronous generator (PMSG) has started widely used according to other generator types due to its superior characteristics, such as a low wind speed and the highest power-to-weight ratio in a direct drive [3], [4].

Grid codes require low-voltage ride-through (LVRT) capability for the wind energy conversion system (WECS) during grid fault conditions. LVRT capability is implemented to protect the wind turbine and maintain a connection during grid fault conditions [5]. The LVRT grid codes differ according to requirements of the Transmission System Operator (TSO) in each country [6]. The LVRT grid codes of some Europe countries are given in [5], [7]. Each country has recovery voltage's different values. A control

Manuscript received 22 October, 2018; accepted 3 February, 2019. method cannot implement to all types of wind generators and all countries due to grid code changes for each country. If a country has weak grid codes, it will need more reactive power support during grid faults [5]. Therefore, many systems have been presented to enhance LVRT capability of PMSG based on wind farm in the literature.

A braking chopper (BC) is implemented to enhance the LVRT capability of a PMSG based on WECS during a voltage dip [8]-[10]. This method has some advantages such as a simple control structure and low cost, but BC does not enhance the power quality at output of WECS. The second method is static synchronous compensator (STATCOM) that voltage regulation is greatly enhanced in both the steady and transient states [11], but STATCOM has disadvantages, such as high cost and additional hardware. In another way, a predictive control protection system is presented as the most successful LVRT strategy for a PMSG based on WECS [12]. However, the predictive control protection system has difficulty implemented to control topologies of grid-side (GSC) and machine-side converter (MSC) because of nonlinearity and uncertainties of power system. However, the proposed fuzzy type 2 system (IT-2 FLC) in this paper provides a full control for PMSG during all grid fault types.

The interval fuzzy type 2 system is presented to enhance LVRT capability for PMSG based on WECS using lowvoltage two-level voltage-source converter (VSC) [13]. Two-level VSC is a widely used converter in WECS according to multilevel converter types, but multilevel converters are more effective than conventional two-level systems for higher power applications based on WECS. The neutral-point clamped (NPC) converter is more suitable for back-to-back applications among other multilevel converter types. The NPC converter has several advantages, such as a simpler structure, good dynamic response, good harmonic spectrum, and decreases voltage values for power electronic switches.

This paper presents an improvement of LVRT capability of a PMSG based on an NPC converter using an interval type-2 fuzzy logic system (IT-2 FLC) protection circuit 
during different voltage dip conditions. The aim of the proposed protection method is to continue connection between PMSG and the grid during a voltage dip and maintain uninterrupted power supply for grid. The main aims of protection method based on IT-2 FLC are to maintain a constant DC link voltage, reduce the amplitude of stator fault voltages, and generally enhance all responses of PMSG. The proposed system prevents the power converters from the damaging effects of over-voltage during a voltage dip. The proposed system implemented a WECS-based 1.5 MVA PMSG for different grid fault conditions using MATLAB/Simulation. It is compared to a system with and without protection for different grid fault conditions, and the effectiveness of presented method is proved by simulation results.

The rest of the paper is organized as follows. Section II summarizes WECS system. A proposed protection control system for improving the low-voltage ride-through of a PMSG based on WECS is introduced in Section III. The design of IT-2 FLC is given in Section IV. The comparative results of simulation studies of the efficiency of the proposed protection system are introduced in Section V. As result, conclusions are given in Section VI.

\section{WIND ENERGY CONVERSION SYSTEM}

The WECS consists of a generator, blade, power electronics, control systems, transformer, and a PCC, as seen in Fig. 1. AWECS plant converts from wind power to electrical power. There are many types of generators used in the WECS, each of which has different advantages and disadvantages. PMSGs are widely used compared to other generator types due to their superior characteristics, such as a low wind speed and the highest power-to-weight ratio in a direct drive. MSC and GSC systems consist of an NPC system each using 12 IGBT. The NPC system is more effective than conventional two-level converter systems for higher power applications based on WECS.

\section{A. Wind Turbine Characteristics}

Any wind turbine' mechanical power is obtained in (1) [14]

$$
P_{m}=\frac{1}{2} \rho A C_{p}(\lambda, \beta) V_{\omega}^{3}
$$

where $C_{p}$, which depicts the power coefficient, varies with $\beta$ and $\lambda$ of wind turbine. $A$ depicts area swept by blade. $\lambda$ depicts a nonlinear function of TSR and $\rho$ represents air density. $\beta$, which depicts pitch angle, is obtained according to producer data [14]. $V_{\omega}$ represents the wind speed. The $\lambda$ equation is (2)

$$
\lambda=\frac{\omega_{r} r}{V_{\omega}}
$$

where $\omega_{r}$ depicts rotor speed and $r$ represents blade radius.

The relationship between WT's speed and maximum power point is obtained in (1). As shown in (1), the maximum active power $\left(P_{m}\right)$ changes linearly with wind speed.
$C_{p}$ has been a maximum power value obtained from the wind by WT for a specific value of $\lambda_{o p}$. WT is operated at optimum speed to achieve maximum power efficiency even during wind variations.

\section{B. Mathematical Model of PMSG}

The PMSG voltage equations are illustrated in (3), where $R_{s}$ and $L_{s}$ represent stator resistance and inductance, respectively. $\omega_{e}$ depicts electric angular frequency. $v_{s}$ denotes a terminal voltage generated by PMSG described in (3) $[14]-[17]$

$$
\left(\begin{array}{c}
v_{s d} \\
v_{s q}
\end{array}\right)=R_{s}\left(\begin{array}{c}
i_{s d} \\
i_{s q}
\end{array}\right)+\frac{d}{d t}\left(\begin{array}{c}
L_{d} i_{s d} \\
L_{q} i_{s q}
\end{array}\right)+\omega_{e}\left(\begin{array}{c}
-\psi_{s q} \\
\psi_{s d}
\end{array}\right) .
$$

The stator's flux linkages (dq frame) are obtained in (4):

$$
\left(\begin{array}{l}
\psi_{s d} \\
\psi_{s q}
\end{array}\right)=\left(\begin{array}{cc}
L_{d} & 0 \\
0 & L_{q}
\end{array}\right) \times\left(\begin{array}{c}
i_{s d} \\
i_{s q}
\end{array}\right)+\psi_{f}\left(\begin{array}{l}
1 \\
0
\end{array}\right),
$$

where $\psi_{s d}$ and $\psi_{s q}$ are the flux linkages. $\psi_{f}$ represents the flux linkage in the permanent magnets. $L_{d}$ and $L_{q}$ represent stator inductances in the $d q$ frame. $i_{s d}$ and $i_{s q}$ represent generator $d q$ frame currents.

The voltage equations of $d q$ frame are obtained in (5)

$$
\left(\begin{array}{c}
v_{s d} \\
v_{s q}
\end{array}\right)=R_{s}\left(\begin{array}{c}
i_{s d} \\
i_{s q}
\end{array}\right)+\frac{d}{d t}\left(\begin{array}{c}
L_{d} i_{s d} \\
L_{q} i_{s q}
\end{array}\right)+\omega_{e}\left(\begin{array}{c}
-L_{q} i_{s q} \\
L_{d} i_{s d}
\end{array}\right)+\omega_{e}\left(\begin{array}{c}
0 \\
\psi_{f}
\end{array}\right),
$$

where $v_{s d}$ and $v_{s q}$ are voltages of the $d$ and $q$ loops in the stator, respectively. The voltages of the $v_{s d}$ and $v_{s q}$ are utilized to generate the reference three-phase sinusoidal voltage. $i_{s d}$ and $i_{s q}$ depict currents of $d$ and $q$ loops in stator, respectively. $L_{d}$ and $L_{q}$ represent inductances of $q$ and $d$ loops in the stator, respectively. $R_{s}$ denotes stator resistor, and $\omega_{e}$ is electrical angular of PMSG.

\section{Proposed PRotection CONTROL SYSTEM}

The proposed control structure of a PMSG using IT-2 FLC is given in Fig. 1. The IT-2 FLC has more new features than conventional control systems, such as numerical uncertainties and modelling the uncertainties in the linguistic variables. The parameters of a proportional-integral (PI) are difficult to adjust for a WECS based on high nonlinearity with uncertain operating conditions. PI controller supplies proper performance for a given operating point. However, conventional controller has poor transient performance due to continuously varying the dynamics of WECS based on PMSG during all fault conditions. Thus, the performance of the designed conventional control method is reduced when the operating conditions of WECS based on a PMSG are highly uncertain.

The parameters in the conventional control method are to be frequently readjusted to sustain normal performance and to cope with the uncertainties of a WECS based on a PMSG. Therefore, new methods are investigated to overcome the numerical uncertainties and new linguistics. The type-2 fuzzy set is a new method with specific characteristics. Thus, the special characteristics of IT-2 FLC are used to improve wind energy conversion systems. 


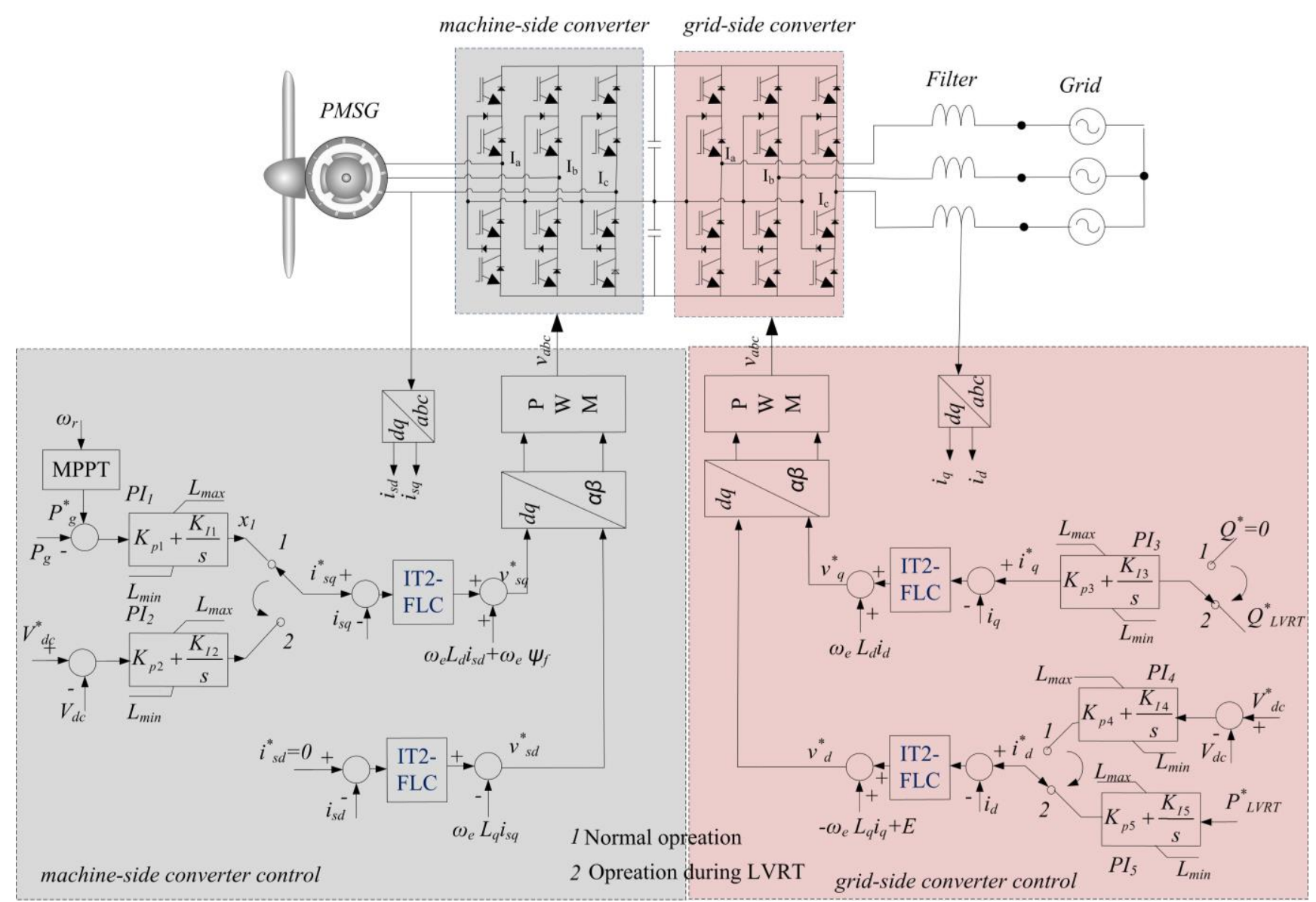

Fig. 1. Control structure of PMSG based on WECS.

\section{A. MSC Control}

A control diagram of MSC is seen in Fig. 1. This block diagram consists of dq frame currents of PMSG. The pulsewidth modulation (PWM) method is implemented to obtain the duty cycles of voltage commands by means of an IT2FLC and a PI. Two large capacitors are applied to find a neutral point $\mathrm{N}$. The MSC control has two switch modes. First mode is to normal operation mode. A q-axis current component is determined by stator active power $(P)$, and the $\mathrm{d}$-axis current component equals zero during normal operation conditions. In Fig. 1, reference voltages $\left(v^{*}{ }_{s q}\right.$ and $v^{*}{ }_{s d}$ ) are calculated by the following formula

$$
\left(\begin{array}{c}
v_{s d}^{*} \\
v_{s q}^{*}
\end{array}\right)=\left(\begin{array}{c}
V_{s d}^{\prime} \\
V_{s q}^{\prime}
\end{array}\right)+\omega_{e}\left(\begin{array}{c}
-L_{q} i_{s q} \\
L_{d} i_{s d}
\end{array}\right)+\omega_{e}\left(\begin{array}{c}
0 \\
\psi_{f}
\end{array}\right) .
$$

Second mode is LVRT mode during the grid-voltage dip. The q-axis current is determined by a DC link voltage during LVRT operation. MSC arranges a DC link voltage with IT-2 FLC during LVRT operation.

\section{B. GSC Control}

A control diagram of GSC is seen in Fig. 1. The GSC control has two switch modes. First mode is to normal operation. In normal operation condition, GSC control inputs consist of two loops, which is a reactive power control and DC link voltage system. The GSC control regulates a reactive power and DC link voltage of the wind turbine. A stator reactive power $(Q)$ is obtained by q-axis component, whereas DC Link voltage $\left(V_{d c}\right)$ is obtained from d-axis component. In Fig. 1, reference voltages $\left(v^{*}{ }_{q}\right.$ and $\left.v^{*}{ }_{d}\right)$ are calculated by the following formula

$$
\left(\begin{array}{c}
v_{d}^{*} \\
v_{q}^{*}
\end{array}\right)=\left(\begin{array}{c}
V_{d}^{\prime} \\
V_{q}^{\prime}
\end{array}\right)+\omega_{e}\left(\begin{array}{c}
-L_{q} i_{q} \\
L_{d} i_{d}
\end{array}\right)+\left(\begin{array}{c}
E \\
0
\end{array}\right) .
$$

Second mode is to LVRT mode during a grid-voltage dip. The $\mathrm{d}$-axis current component is determined by LVRT power $\left(P^{*}{ }_{L V R T}\right)$ during LVRT operation. The GSC regulates the LVRT powers of the system with the proposed control.

\section{TYPE 2 FuZZY LOGIC SET DESIGN}

The block diagram for the IT-2 FLC is given in Fig. 2. An open source IT2-FLS Matlab/ Simulink toolbox produced by Taskin and Kumbasar [18] is used in this study. An IT-2 FLC uses a fuzzy logic rule based on data analysis system. The basic structure of IT-2 FLC consists of four components. At first, the fuzzier converts from crisp input signal to fuzzy inputs. The inference mechanism is formed using fuzzy reasoning to obtain a fuzzy output. The type reducer converts from a Type-2 Fuzzy Set to a Type- 1 Fuzzy Set and finally obtains crisp output using various defuzzification techniques.

The proposed structure of IT-2 FLC is given in Fig. 3. The reference current value $\left(I_{d}\right)$ of GSC controller is generated from DC link voltage during normal operation or from $P_{L V R T}^{*}$ during the voltage dip. The reference current value $\left(I_{q}\right)$ of GSC controller is generated from the reactive 
power (0) value during normal operation or from $Q^{*}{ }_{L V R T}$ during a voltage dip.

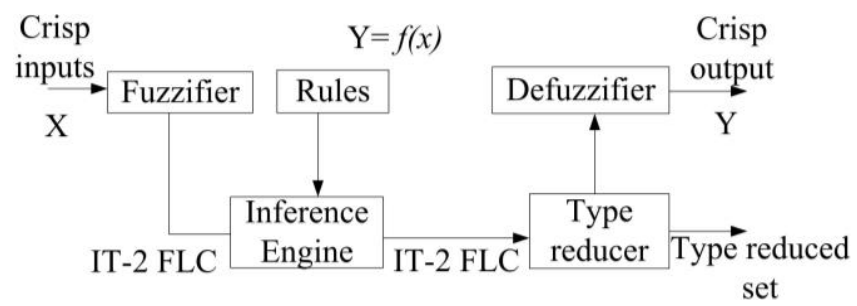

Fig. 2. The general block diagram of IT-2.

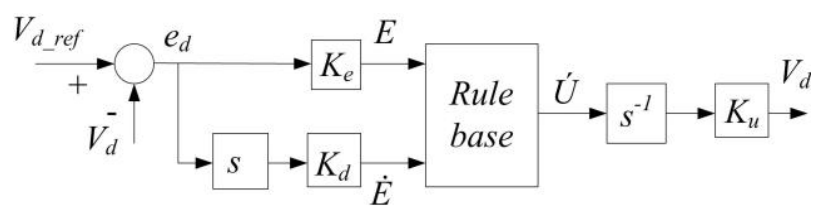

Fig. 3. Proposed structure of IT-2 FLC.

The error signals are derived as:

$$
\begin{aligned}
& e_{d}=V_{d r e f}-V_{d}, \\
& e_{q}=V_{\text {qref }}-V_{q},
\end{aligned}
$$

where $e_{d}$ and $e_{q}$ depict error signals. The inputs of the final controller are expressed by:

$$
\begin{aligned}
& E=K_{e} e_{d}, \\
& \dot{E}=K_{d} \dot{e}_{d} .
\end{aligned}
$$

The $\dot{e}_{d}$ and $\dot{e}_{q}$ depict the derivatives of the error signals, and $K_{e}$ and $K_{d}$ depict controller gains.

\section{A. Fuzzification}

The membership functions of the error signals are fuzzified using five triangular shapes. The fuzzy sets are identified as PL-Positive Large, PS-Positive Small, Z-Zero, NL-Negative Large, and NS-Negative Small. The designed membership functions for IT-2 FLC are given in Fig. 4.

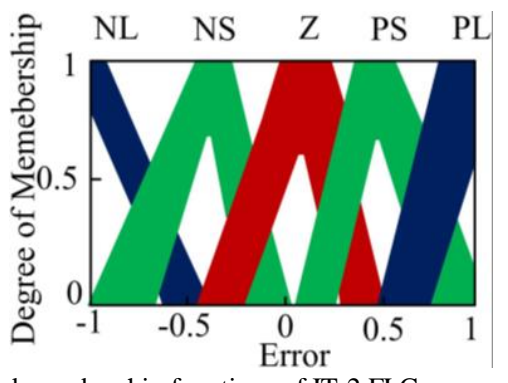

Fig. 4. Designed membership functions of IT-2 FLC.

The membership functions with an equal width and span of FOU are used in most studies, but this application does not represent the best performance of IT-2 FLC. The membership functions are selected using information from various simulation results in this study. The width of the FOU is regulated according to the oscillation of DC link voltage and output powers. The maximum and minimum values for all outputs and inputs are selected as +1 to -1 [18].

\section{B. Inference Engine}

The inference engine has three type operations based on the rule implication, aggregation and type reduction. The fuzzy mapping of the input variables consists of IF-THEN rules expressed by

If $\left(e_{d}\left(e_{q}\right)\right.$ is $\left.x_{1}\right)$ and $\left(\dot{e}_{d}\left(\dot{e}_{q}\right)\right.$ is $\left.y_{1}\right)$, then $\left(V_{d}\left(V_{q}\right)\right.$ is $\left.w_{1}\right)$.

All 25 rules and membership functions for IT-2 FLC are selected. The inference system uses the max method for the Join aggregation and operation and the min-method for the Meet implication and operation [18].

\section{Defuzzification}

The Karnik-Mendel algorithm is implemented in this study as a defuzzification method. The Karnik-Mendel algorithm identifies the largest and smallest elements among the centroids. This method converts from fuzzy to crisp system output values

$$
y(x)=\frac{y_{1}+y_{r}}{2}
$$

where $y_{r}$ and $y_{l}$ depict the output of the IT - 2 fuzzy system. The average of $y_{r}$ and $y_{l}$ is used to defuzzify the output of the IT - 2 fuzzy system [18].

\section{Simulation Results}

A block diagram of PMSG based on WECS method is given for verification using an IT-2 FLC in Fig 1. Three different cases of the LVRT are analysed for PMSG-based on WECS using an IT-2FLC control system in Matlab/Simulink. This Simulink operation is used two switching methods based on the normal and LVRT operation systems. PI and IT-2FLC control systems for the two converter systems are implemented to improve during the normal operation and LVRT operation. The MSC inputs are $i^{*}{ }_{s d}$ and $P_{g}^{*}$ during normal operation and are $i^{*}{ }_{s d}$ and $V_{d c}$ during LVRT operation. The GSC inputs are $V_{d c}$ and $Q^{*}$ during normal operation and are $P_{\text {LVRT }}^{*}$ and $Q_{\text {LVRT }}^{*}$ during LVRT operation.

The MSC enhances the active power requirement during normal operation. The GSC maintains a nearly constant DC link voltage during normal operation. The MSC maintains a nearly constant DC link voltage during LVRT operation due to the switching method. The GSC enhances the active power requirement during LVRT operation due to the switching method.

\section{A. Scenario 1}

The simulation results of PMSG based on WECS are given with and without proposed control system during a voltage-dip of $(90 \%)$. As seen in Fig. 5(a), when the voltage dip occurred, DC link voltage increases from a nominal value of $1150 \mathrm{~V}$ to $4000 \mathrm{~V}$ without proposed system. However, the DC link voltage maintains a nominal value of $1150 \mathrm{~V}$ with proposed system in Fig. 5(c). The rotor speed increases at 3 p.u. without the protection system, and it maintains a nominal value of 1.2 p.u. with the protection system in Fig. 5(b). The active power suddenly reduces to zero without the protection system during a voltage dip and is fixed at 1 p.u. with the protection system during voltage 
dip in Fig. 5(d). The reactive power suddenly rises to 1 p.u. without the protection system during a voltage-dip and is fixed at 0 p.u. with the protection system during voltage dip in Fig. 5(e). The electromagnetic torque value reduces to 0 p.u. without the protection system, but it is fixed at 1 p.u. with the protection system even after and during a grid fault in Fig. 5(f). The DC link voltage, electromagnetic torque, rotor speed, active, and reactive power are enhanced due to the control action of the proposed protection system. A voltage dip of $(90 \%)$ is serious compared to other fault types. Therefore, this type of voltage dip is quite difficult to control during LVRT. Thus, as seen from the compared results, the proposed protection provides full control of the PMSG.

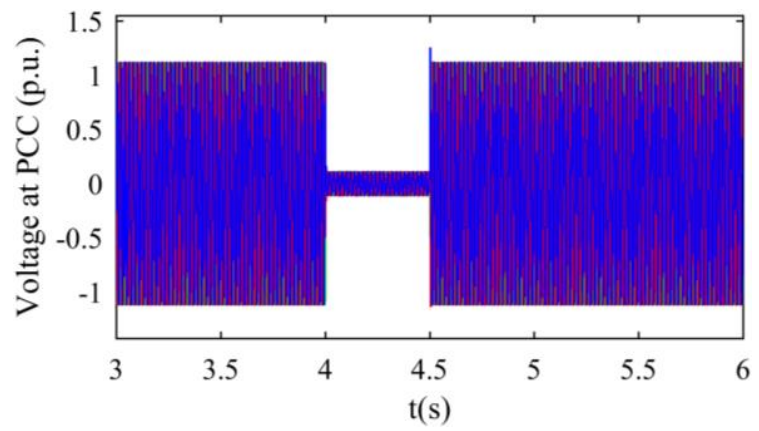

(a)

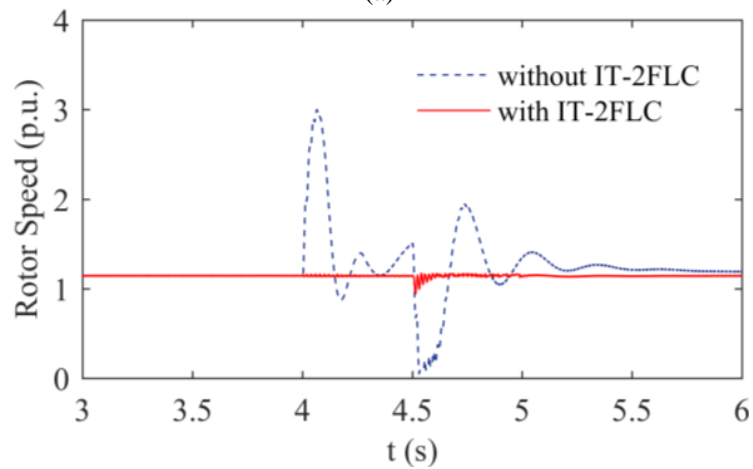

(b)

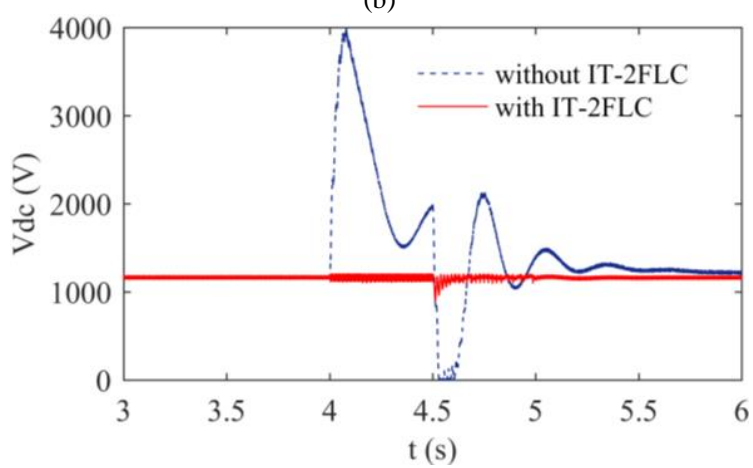

(c)

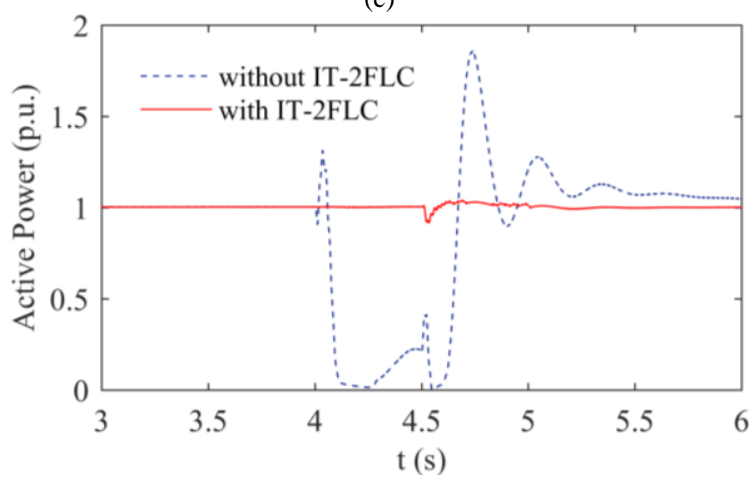

(d)

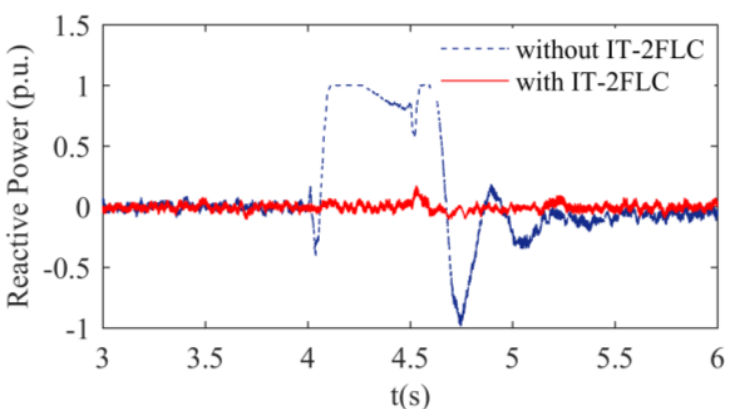

(e)

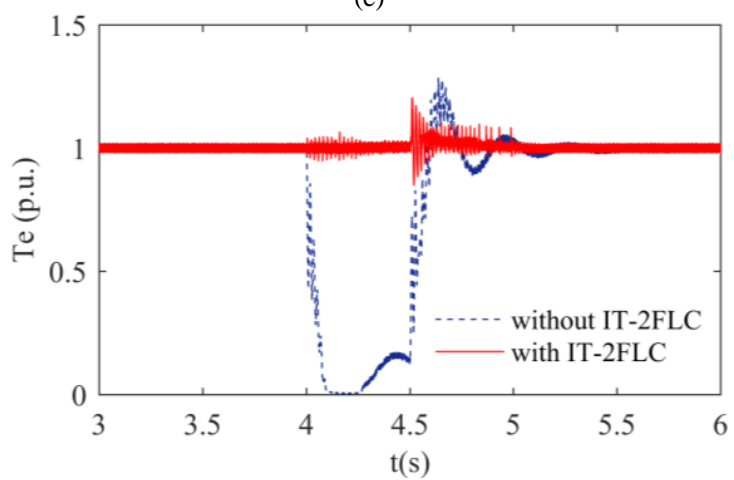

(f)

Fig. 5. Dynamic response of a 1.5 MVA PMSG with and without a protection system during a voltage-dip $(90 \%)$.

\section{B. Scenario 2}

The simulation results of a PMSG based on WECS are given with and without a protection control system during a voltage-dip of $(50 \%)$. This voltage dip is applied between $4.0 \mathrm{~s}$ and $4.5 \mathrm{~s}$ in Fig. 6(a). As seen in Fig. 6, when the voltage dip occurs, DC link voltage increases from a nominal value of $1150 \mathrm{~V}$ to $2700 \mathrm{~V}$ without proposed system. However, it maintains a nominal value of $1150 \mathrm{~V}$ with a protection system in Fig. 6(c). The rotor speed increases to 2.2 p.u. without the protection system and maintains a nominal value of 1.2 p.u. with the protection system in Fig. 6(b). The active power suddenly reduces to 0.4 p.u. without the protection system during a voltage dip and is fixed at 1 p.u. with the protection system during voltage dip in Fig 6(d). The reactive power suddenly rises to 0.6 p.u. without the protection system during a voltage dip and is fixed at 0 p.u. with the protection system during voltage dip in Fig. 6(e). The average electromagnetic torque value decreases to $0.4 \mathrm{p}$.u without the protection system but is fixed at 1 p.u. with the protection system even after and during a grid fault in Fig. 6(f). The DC link voltage, electromagnetic torque, rotor speed, active, and reactive power are enhanced due to the control action of the proposed protection system.

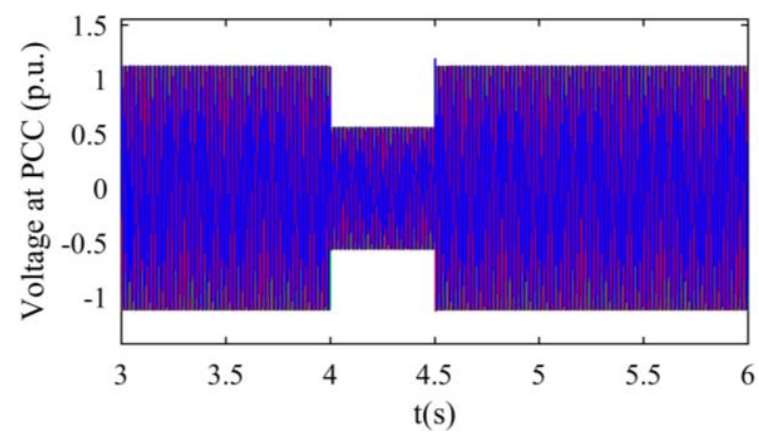

(a) 


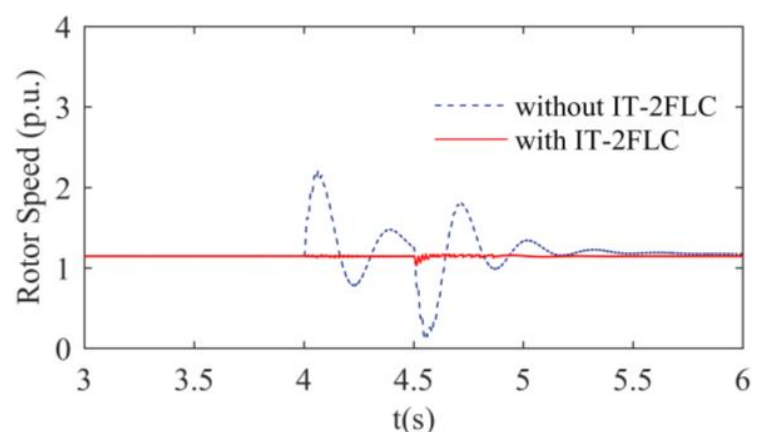

(b)

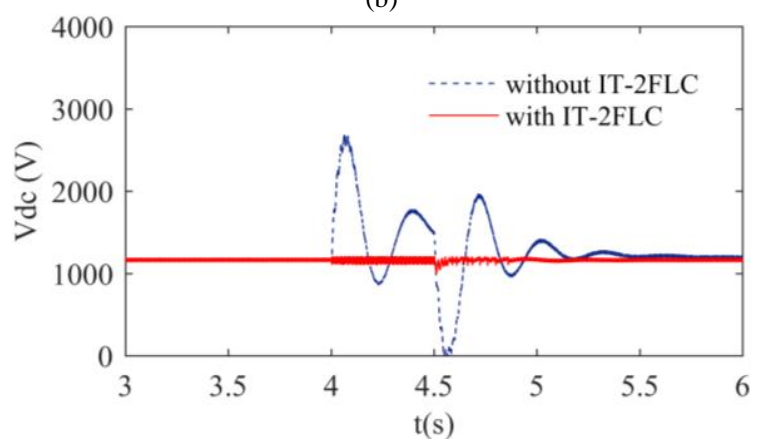

(c)

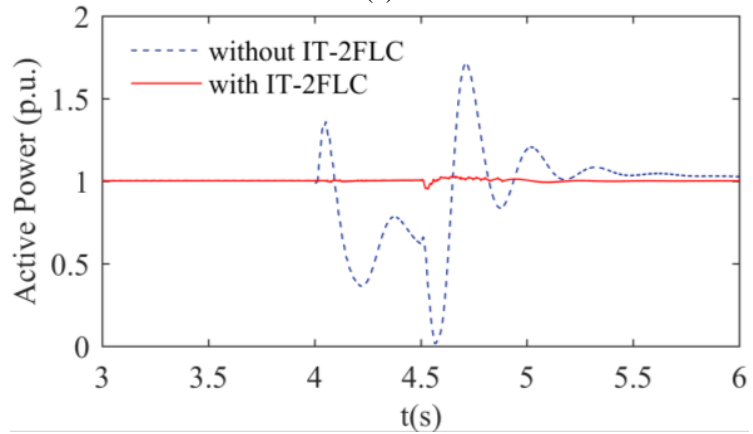

(d)

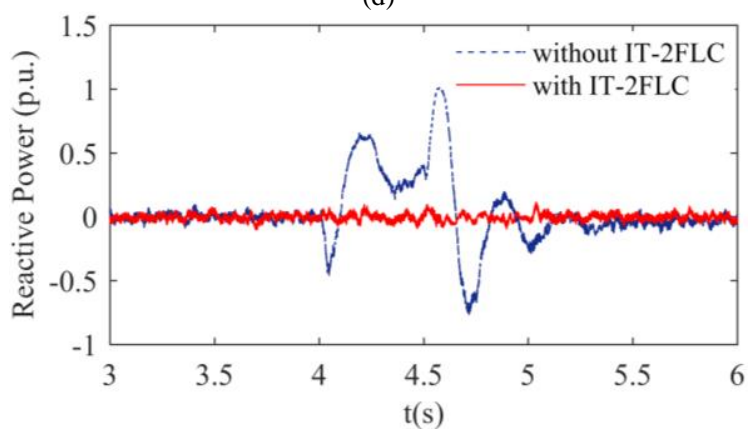

(e)

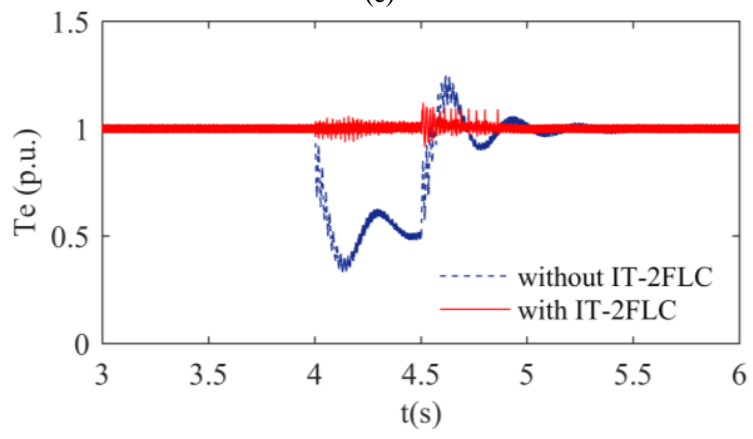

(f)

Fig. 6. Dynamic response of a 1.5 MVA PMSG with and without a protection system during a voltage-dip $(50 \%)$.

As seen from the compared results, the proposed protection provides full control of the PMSG.

\section{Scenario 3}

The simulation results of a PMSG based on WECS are given with and without a protection control system during a voltage dip (25\%). This voltage dip is implemented between $4.0 \mathrm{~s}$ and $4.5 \mathrm{~s}$ in Fig. 7(a). As seen in Fig. 7(c), when the voltage dip occurs, the DC link voltage increases from a nominal value of $1150 \mathrm{~V}$ to $1900 \mathrm{~V}$ without proposed system, and it maintains a nominal value of $1150 \mathrm{~V}$ with the protection system. The rotor speed increases to 1.6 p.u. without the protection system, and it maintains a nominal value of 1.2 p.u. with the protection system in Fig. 7(b). The active power suddenly reduces to 0.65 p.u. without the protection system during a voltage dip and is fixed at 1 p.u. with the protection system during voltage dip in Fig. 7(d). The reactive power suddenly rises to 0.3 p.u. without the protection system during a voltage dip and is fixed at 0 p.u. with the protection system during voltage dip in Fig. 7(e). The electromagnetic torque value reduces to an average of 0.7 p.u. without the protection system, but the value is fixed 1 p.u. with the protection system even after and during a grid fault in Fig. 7(f). DC link voltage, electromagnetic torque, rotor speed, active, and reactive power are enhanced due to the control action of the proposed protection system. As seen from the compared results, the proposed protection provides full control of the PMSG.

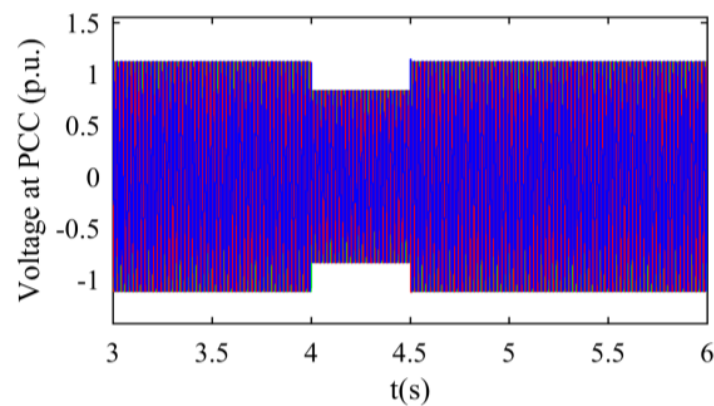

(a)

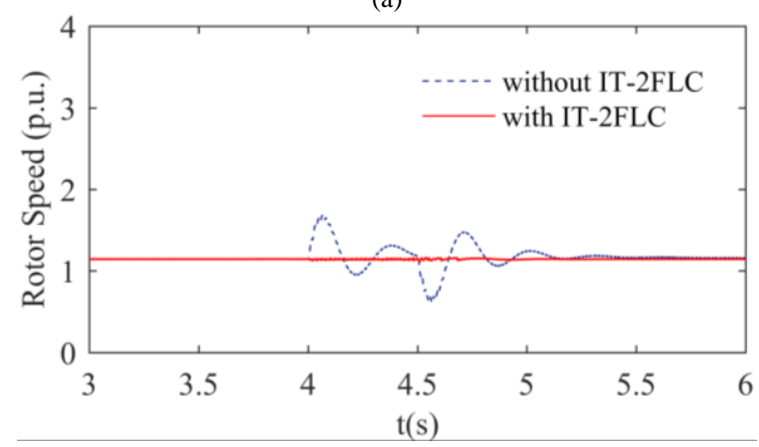

(b)

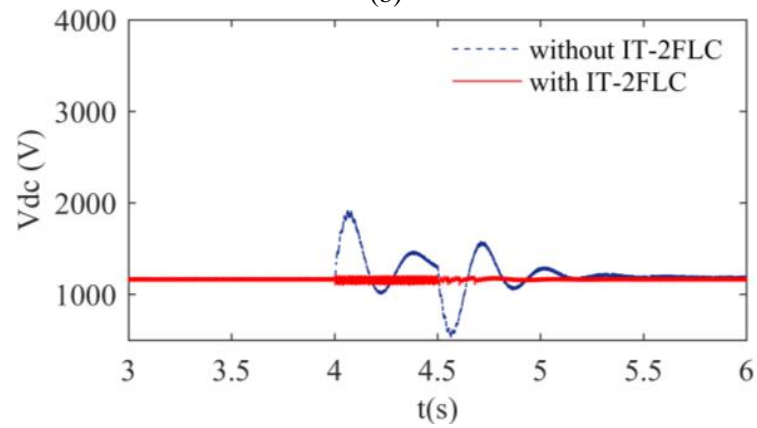

(c) 


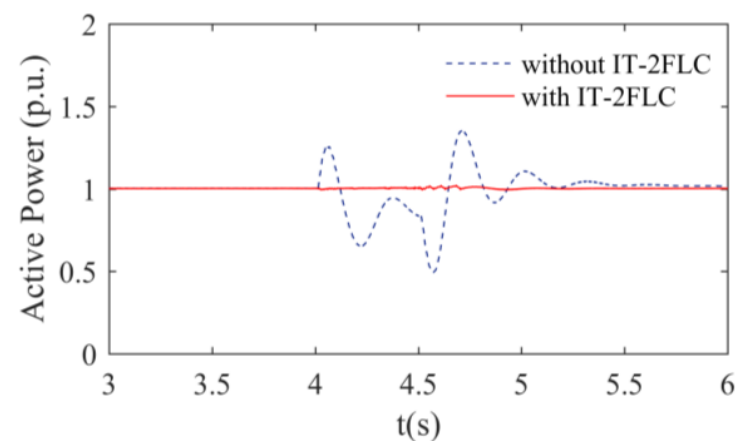

(d)

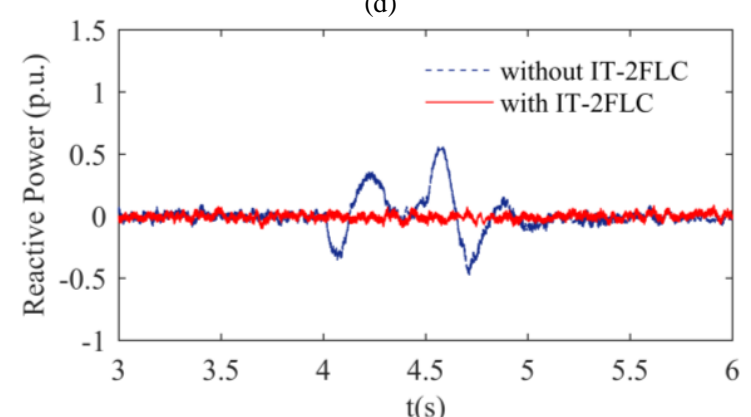

(e)

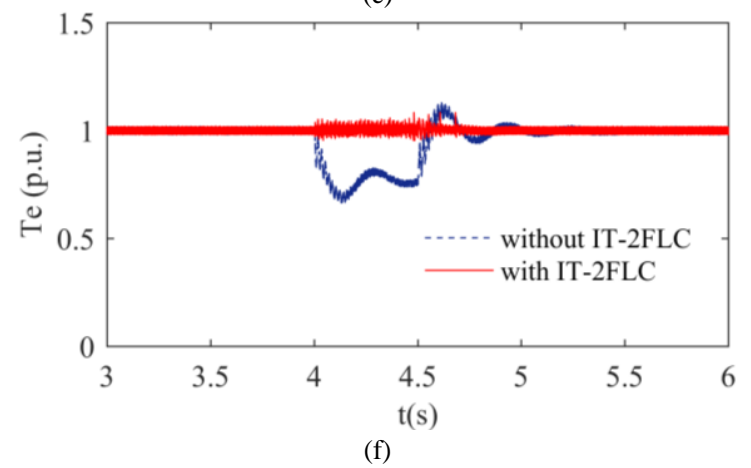

Fig. 7. Dynamic response of a 1.5 MVA PMSG with and without a protection system during a voltage-dip $(25 \%)$.

A voltage dip of (25\%) is slight compared to other fault types. However, it is the most common type.

\section{CONCLUSIONS}

This paper presents an enhancement of LVRT capability of a PMSG based on WECS with IT-2FS during different voltage sag conditions. Three different cases of voltage sag are analysed using IT-2FLC. The proposed protection system is implemented to enhance the LVRT capability of a PMSG based on WECS, even after and during different voltage sag conditions.

A voltage dip of $(90 \%)$ is serious compared to other voltage sag types. Therefore, it is quite difficult to control during LVRT. A voltage dip of (25\%) is slight compared to other voltage dip types. However, it is the most common type of voltage dip. Thus, as seen from the compared results, the proposed protection provides full control of PMSG and prevents from damage effects of the overvoltage during voltage dips.

During a voltage dip of $(90 \%)$, DC link voltage rises from a nominal value of $1150 \mathrm{~V}$ to $4000 \mathrm{~V}$ without a protection system. During a voltage dip of $(50 \%)$, DC link voltage rises from a nominal value of $1150 \mathrm{~V}$ to $2700 \mathrm{~V}$ without a protection system. During a voltage dip of ( $25 \%)$, DC link voltage rises from a nominal value of $1150 \mathrm{~V}$ to
1900 V without proposed system. However, DC link voltage maintains a nominal value of $1150 \mathrm{~V}$ with proposed system for all voltage dip types.

The active power suddenly decreases to zero without the protection system during a voltage-dip of $(90 \%)$. It decreases to 0.4 p.u. without the protection system during a voltage dip of $(50 \%)$, and decreases to 0.65 p.u. without the protection system during a voltage dip of $(25 \%)$. However, the active power value remains nearly 1 p.u. with the proposed protection system for all voltage dip types.

The proposed protection system has a very small settling time, drop and peak value compared to a no-protection system and performs better than a no-protection system during different voltage sag conditions. Finally, as seen from the compared results, the proposed protection system provides full control of PMSG and prevents from damage effects of the overvoltage during a voltage sag.

\section{REFERENCES}

[1] Y. Li, Z. Xu, K. P. Wong, "Advanced control strategies of PMSGbased wind turbines for system inertia support", in IEEE Trans. Power Systems, vol. 32, no. 4, pp. 3027-3037, 2017. DOI: 10.1109/TPWRS.2016.2616171.

[2] Z. Zhang, F. Wang, J. Wang, J. Rodriguez, R. Kennel, "Nonlinear direct control for three-level NPC back-to-back converter PMSG wind turbine systems: experimental assessment with FPGA", in IEEE Trans. Industrial Informatics, vol. 13, no. 3, pp. 1172-1183, 2017. DOI: 10.1109/TII.2017.2678500.

[3] M. Abdelrahem, C. Michael Hackl, R. Kennel, "Simplified model predictive current control without mechanical sensors for variablespeed wind energy conversion systems", Electrical Engineering, vol. 99, pp. 367-377, 2017. DOI: 10.1007/s00202-016-0433-y.

[4] A. Bonfiglio, F. Delfino, F. Gonzalez-Longatt, R. Procopio, "Steadystate assessments of PMSGs in wind generating units", International Journal of Electrical Power \& Energy Systems, vol. 90, pp. 87-93, 2017. DOI: 10.1016/j.ijepes.2017.02.002.

[5] A. Rini Ann Jerin, P. Kaliannan, U. Subramaniam, "Improved fault ride through capability of DFIG based wind turbines using synchronous reference frame control based dynamic voltage restorer", ISA Transactions, vol. 70, pp. 465-474, 2017. DOI: 10.1016/j.isatra.2017.06.029.

[6] A. O. Ibrahim, T. H. Nguyen, D. C. Lee, S. C. Kim, “A fault ridethrough technique of DFIG Wind turbine systems using dynamic voltage restorers", IEEE Trans. Energy Conversion, vol. 26, no. 3, pp. 871-882, 2011. DOI: 10.1109/TEC.2011.2158102.

[7] K. H. Kim, Y. C. Jeung, D. C. Lee, H. G. Kim, "LVRT scheme of PMSG wind power systems based on feedback linearization", IEEE Trans. Power Electronics, vol. 27, no. 5, pp. 2376-2384, 2012. DOI: 10.1109/TPEL.2011.2171999.

[8] J. F. Conroy, R. Watson, "Low-voltage ride-through of a full converter wind turbine with permanent magnet generator", IET Renewable Power Generation, vol. 1, no. 3, pp. 182-189, 2007. DOI: 10.1049/iet-rpg:20070033.

[9] S. Yang, T. Zhou, D. Sun, Z. Xie, X. Zhang, "A SCR crowbar commutated with power converter for DFIG-based wind turbines", International Journal of Electrical Power \& Energy Systems, vol. 81, pp. 87-103, 2016. DOI: 10.1016/j.ijepes.2016.01.039.

[10] M. Nasiri, J. Milimonfared, S. H. Fathi, "A review of low-voltage ride-through enhancement methods for permanent magnet synchronous generator based wind turbines", Renewable and Sustainable Energy Reviews, vol. 47, pp. 399-415, 2015. DOI: 10.1016/j.rser.2015.03.079.

[11] H. Geng, L. Liu, R. Li, "Synchronization and reactive current support of PMSG-based wind farm during severe grid fault", IEEE Trans. Sustainable Energy, vol. 9, no. 4, pp. 1596-1604, 2018. DOI: 10.1109/TSTE.2018.2799197.

[12] Calle-Prado, S. Alepuz, J. Bordonau, P. Cortes, J. Rodriguez, "Predictive control of a back-to-back NPC converter-based wind power system", IEEE Trans. Industrial Electronics, vol. 63, no. 7, pp. 4615-4627, 2016. DOI: 10.1109/TIE.2016.2529564.

[13] H. M. Yassin, H. H. Hanafy, M. M. Hallouda, "Enhancement low- 
voltage ride through capability of permanent magnet synchronous generator-based wind turbines using interval type-2 fuzzy control", IET Renewable Power Generation, vol. 10, no. 3, pp. 339-348, 2016. DOI: 10.1049/iet-rpg.2014.0453.

[14] C.-M. Hong, C.-H. Chen, C. S. Tu, "Maximum power point trackingbased control algorithm for PMSG wind generation system without mechanical sensors", Energy Conversion and Management, vol. 69 pp.58-67, 2013. DOI: 10.1016/j.enconman.2012.12.012.

[15] J. Yao, M. Yu, W. Gao, X. Zeng, "Frequency regulation control strategy for PMSG wind-power generation system with flywheel energy storage unit", IET Renewable Power Generation, vol. 11, no. 8, pp. 1082-1093, 2017. DOI: 10.1049/iet-rpg.2016.0047.
[16] A. M. Eltamaly, H. M. Farh, "Maximum power extraction from wind energy system based on fuzzy logic control", Electric Power Systems Research, vol. 97, pp. 144-150, 2013. DOI: 10.1016/j.epsr.2013.01.001.

[17] A. Calle-Prado, S. Alepuz, J. Bordonau, P. Cortes, J. Rodriguez, "Predictive control of a back-to-back NPC converter-based wind power system", IEEE Trans. Industrial Electronics, vol. 63, no. 7, pp. 4615-4627, 2016. DOI: 10.1109/TIE.2016.2529564

[18] A. Taskin, T. Kumbasar, "An open source Matlab/Simulink toolbox for interval type-2 fuzzy logic systems", IEEE Symposium Series on Computational Intelligence, Cape Town, South Africa, 2015, pp. 1561-1568. DOI: 10.1109/SSCI.2015.220. 